\title{
Cevap Yüzey Yöntemi Kullanılarak Poli(VPi-ko-MA) / Grafen Kompozitlerinin İletkenliğinin Optimizasyonu
}

\author{
Gülben TORĞUT* \\ Munzur Üniversitesi, Tunceli Meslek Yüksekokulu, Kimya ve Kimyasal İşlemeler Bölümü, Tunceli \\ (ORCID: 0000-0003-1730-1152)
}

\begin{abstract}
Öz
$\mathrm{Bu}$ çalışmada, öncelikle poli(Vinil pivalat-ko-Maleik anhidrit) [poli(VPi-ko-MA)] kopolimeri serbest radikalik polimerizasyon yöntemiyle $65^{\circ} \mathrm{C}$ 'de 24 saat süreyle sentezlenmiştir. FT-IR ile karakterize edilen kopolimerin kütlece farklı miktarlarda Grafen (GF) içeren kompozitleri çözelti döküm tekniği ile hazırlanmıştır. Kompozitler FT-IR ve SEM teknikleri ile karakterize edilmiştir. Uygulanan voltaj, frekans ve GF içeriği arasında kantitatif bir ilişki elde etmek için cevap yüzey yöntemi (CYY) kullanılmıştır. Ölçülen cevap, kompozitlerin elektriksel (AC) iletkenliğidir. Modeldeki parametrelerin (frekans, voltaj ve GF miktarı) önemi, varyans analizi ile belirlenmiştir (ANOVA). Model, maksimum elektriksel iletkenliği, $1619 \mathrm{~Hz}$ frekansta, voltaj 15.56 V'da ve GF miktarı ağırlıkça \% 9.99 için $6.93 \times 10^{-8} \mathrm{~S} \mathrm{~cm}^{-1}$ olarak öngörmüştür.
\end{abstract}

Anahtar kelimeler: Polimer/GF kompozit, İletkenlik, Cevap yüzey yöntemi, ANOVA.

\section{Optimization of Conductivity of Poly (VPi-co-MA) / Graphene Composites by Using Response Surface Method}

\begin{abstract}
In this study, firstly Poly(Vinyl pivalate-co-Maleic anhydride) [poly(VPi-co-MA)] copolymer was synthesized by Free radical polymerization method at $65^{\circ} \mathrm{C}$ for 24 hours. The composites of the copolymer characterized by FTIR containing different amounts of Graphene (GF) were prepared by solution casting technique. Composites were characterized by FT-IR and SEM techniques. Response surface method (RSM) was used to obtain a quantitative relationship between applied voltage, frequency and GF content. The measured response is the electrical conductivity of the composites. The importance of parameters (frequency, voltage, and GF amount) in the model was determined by variance analysis (ANOVA). The model predicted maximum electrical conductivity as $6.93 \times 10^{-8} \mathrm{~S} \mathrm{~cm}-1$ for frequency at $1619 \mathrm{~Hz}$, voltage at $15.56 \mathrm{~V}$, and GF amount $9.99 \%$.
\end{abstract}

Keywords: Polymer / GF composite, Conductivity, Response surface method, ANOVA.

\section{Giriş}

Gündelik hayatımızda polimerden yapılmış malzemeler sık karşımıza çıkmaktadır. Polimerlerin bu şekilde yaygın kullanılmalarının en önemli sebeplerinden biri elde edilen bir polimerin eksik bulunan özelliğinin kimyasal modifikasyonla ya da karışımlarının hazırlanmasıyla değiştirilebilmesidir. Örneğin, elektronik cihazlarda kullanılan polimerlerin yüksek 1sıl iletkenliğe sahip olmaları istenmektedir. Bu yüzden 1sıl iletken olan polimerler üzerine yapılan çalışmaların sayısı artırılmakta ve polimerlerin mevcut iletkenliklerini iyileştirici katkı maddeleri kullanılmaktadır [1-3].

Günümüzde, nanomalzemeler yapısal özellikleri nedeniyle çok çeşitli uygulamalara sahiptirler. Özellikle, polimer / inorganik kompozitlerin hazırlanmasında dolgu maddesi olarak inorganik nanomalzemelerin kullanımına olan ilgi otomotiv, havacılık, inşaat ve elektronik sanayideki sayısız uygulamaları nedeniyle her geçen gün artmıştır [4-6]. Şimdiye kadar, araştırmaların çoğu,

*Sorumlu yazar: gtorgut@munzur.edu.tr

Geliş Tarihi: 13.05.2019, Kabul Tarihi: 11.11.2019 
montmorillonit tipi katmanlı silikat bileşikleri, sentetik kil $[5,6]$ veya doğal kökenli tabakalara dayanan polimer nanokompozitler üzerine odaklanmıştır. Ancak kil minerallerinin elektriksel ve termal iletkenliği oldukça zayıftır [7-9]. Bu eksikliklerin üstesinden gelmek için, karbon siyahı, karbon nanotüp (CNT) ve karbon nanofiber (CNF) gibi karbon bazlı nano doldurucular polimer nanokompozitlerin hazırlanmasında kullanılmışıı [10]. Bunların arasında CNT'lerin iletken dolgu maddesi [11] olarak çok etkili olduğu kanıtlanmıştır. Ancak CNT'lerin nano dolgu maddesi olarak kullanılmasının tek dezavantajı, yüksek üretim maliyetleridir [12]. Bu nedenle, CNT bazlı kompozit malzemelerin seri üretimi çok zordur ve çalışmalar uygun maliyetli iletken bir malzeme olan grafen üzerine yoğunlaşmıştır.

Grafen, petek bir kristal kafes içinde yoğun bir şekilde paketlenmiş, bir atom kalınlığında düzlemsel $\mathrm{sp}^{2}$ bağlı karbon atomu tabakasına sahip iki boyutlu bir karbon nanofiller olarak kabul edilir. "Evrendeki en ince malzeme" olarak kabul edilir [13]. Grafenin, yüksek termal iletkenlik, üstün mekanik özellikler ve mükemmel elektronik taşıma kapasitesi gibi olağanüstü özelliklere sahip olduğu bilinmektedir [14]. Grafenin kendine özgü bu özellikleri, sayısız cihazda uygulama alanı bulmasını sağlamıştır [15]. Termal ve elektriksel olarak iletken olan nanokompozitler, ultra-ince karbon filmler, elektronik devreler, sensörler, ekranlar ve güneş pilleri bu kullanım alanlarına örnek olarak verilebilir $[16,17]$. Bir nano doldurucu olarak grafen, daha yüksek yüzey alanı, en boy oranı, çekme dayanımı, sahip olduğu ssıl ve elektriksel iletkenlik nedeniyle diğer geleneksel nano doldurucular yerine tercih edilebilir.

Maleik anhidrit (MA), $\mathrm{C}_{4} \mathrm{H}_{2} \mathrm{O}_{3}$ genel formülüne sahip çok fonksiyonlu ve kopolimerizasyon sistemlerinde çok tercih edilen eşsiz bir elektron-alıcı monomerdir. MA içerikli kopolimerler reaktif anhidrit halkası nedeniyle halka açılma tepkimeleri için oldukça elverişlidirler. Bu özelliklerine ek olarak ekonomik olmaları da onları birçok alanda yaygın olarak kullanılabilir hale getirmiştir. Yapıştırıcı özellik gösteren kompozitlerin hazırlanmasında, petrol su karışımlarının ayrılmasında ve mikro elektronikte kullanılmaktadırlar [18].

Cevap Yüzey Yöntemi (CYY) ve faktör tasarımı, deneysel modelleme için yaygın olarak kullanılan matematiksel ve istatistiksel bir tekniktir [19]. Sorunların analizinde ve bağımsız süreç faktörleri arasındaki zorlu ilişkilerin belirlenmesinde başarılı bir yöntemdir. Ayrıca, CYY parametrelerin önemini belirler ve bir süreci optimize eder. Ek olarak, sadeliği ve parametreler arasındaki etkileşimi göz önünde bulundurma kabiliyeti nedeniyle tercih edilir [20]. CYY'ni optimizasyonda kullanmak, minimum deneme sayısıyla daha doğru ve eksiksiz sonuçlar sağlar. CYY beş adımdan oluşur: İstenilen parametrelerin ve seviyelerinin tercihi, uygun tasarımla gerekli testlerin oluşturulması, deneylerin yapılması ve regresyon analizi, optimum çalışma koşulunun hesaplanması ve modelin doğrulanmas1 [21].

Bu çalışmanın amacı, Poli (VPi-ko-MA)/Grafen kompozitinin iletkenliğini tahmin etmek için CYY deney tasarımını kullanmak ve iletkenlik üzerine GF miktarının, frekans ve voltaj gibi farklı önemli parametrelerin etkisini karşılaştırmaktır. Bu çalışmanın daha önce hiç yapılmamış olması dikkat çekicidir ve hazırlanan kompozitlerin hangi şartlarda en iyi iletkenlik göstereceği ilerdeki uygulama alanına 1şık tutacaktır.

\section{Materyal ve Metot}

\subsection{Malzemeler}

Maleik anhidrit, Vinil Pivalat, GF ve Dioksan Sigma'dan satın alınmıştır. 2,2'-azobisizobütironitril (AIBN), kloroformdan yeniden kristalleştirilmiş ve başlatıcı olarak kullanılmıştır. Tüm kimyasallar başka bir işlem yapılmadan alındığı şekilde kullanılmıştır.

\subsection{Kompozit Sentezi}

Poli(VPi-ko-MA) kopolimerini sentezlemek için, geri soğutucu ve azot gazı tüpüne bağlanan 3 boyunlu bir balona $20 \mathrm{ml} \mathrm{1,4-Dioksan} \mathrm{konulmuştur.} \mathrm{Reaksiyon} \mathrm{balonuna} \mathrm{soğuk} \mathrm{ortamda} 1 \mathrm{~g}$ vinil pivalat ve $1 \mathrm{~g}$ maleik anhidrit eklenmiştir. Daha sonra, reaksiyon karışımına $0.02 \mathrm{~g}$ AIBN radikal başlatıcısı ilave edilmiştir. Tamamen çözüldükten sonra, argon gazı karışım içinden 10 dakika boyunca geçirilmiştir. $\mathrm{Bu}$ işlemden sonra, deney balonu $65^{\circ} \mathrm{C}^{\prime}$ ye ayarlanmış yağ banyosuna yerleştirilerek polimerizasyon 
reaksiyonu başlatılmış ve reaksiyon 24 saat sonra sonlandırılmıştır. Konsantre olan polimer çözeltisi soğuk ve fazla dietil eter içinde çöktürülerek süzülmüş ve 24 saat boyunca $40{ }^{\circ} \mathrm{C}$ vakumlu etüvde kurutulmuştur. Kompozit filmler, çözelti döküm tekniği ile hazırlanmıştır. Toz poli(VPi-ko-MA) kopolimeri yaklaşık $10 \mathrm{ml}$ tetrahidrofuran içinde çözülmüştür. Daha sonra ağırlıkça \% 2, 5, 8 ve 10 miktarlarında GF parçacıkları çözelti ile ultrasonik banyoda yarım saat karıştırılarak yuvarlak bir teflon kaba dökülmüştür. Hazırlanan kompozit önce açık havada sonra $45^{\circ} \mathrm{C}^{\prime} \mathrm{de}$ vakum altında birkaç saat kurutulmuştur. Poli(VPi-ko-MA) kopolimeri sentezinin şematik gösterimi Şekil l'de verilmiştir.

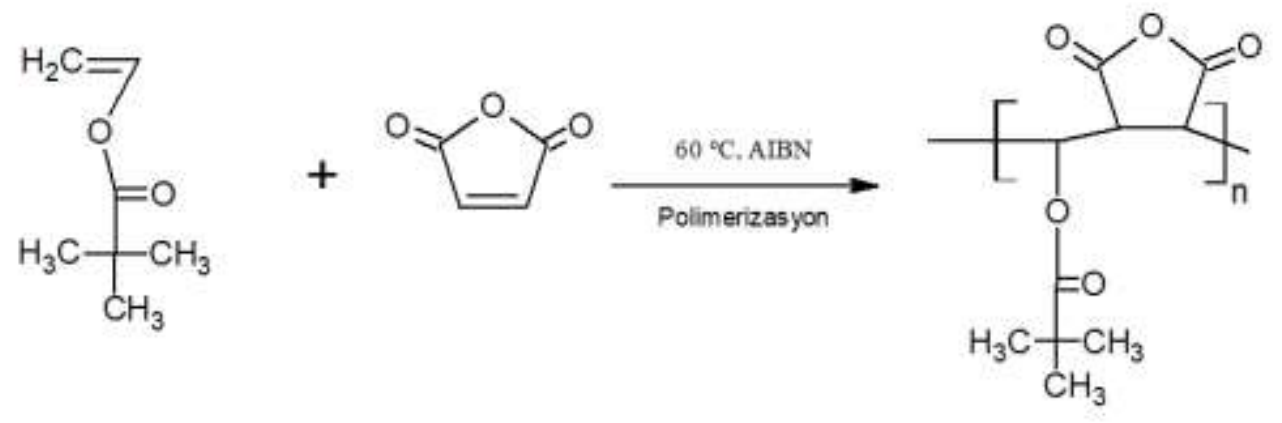

Şekil 1. Kopolimerizasyon reaksiyon şeması

\subsection{Deneysel dizayn}

Bu çalışmada tasarım sürecinin geliştirilmesi, iyileştirilmesi ve optimize edilmesi için bir deney yöntemi olan CYY, çalışma parametrelerinin olası etkileşimlerindeki önemini araştırmak için kullanılmıştır. Merkezi kompozit tasarım (MKT), istatistiksel analiz yapmak ve regresyon modelini oluşturmak için Tasarım Uzman Yazılımı, sürüm 7.0.0 kullanılarak oluşturulmuştur. ANOVA (Varyans Analizi) kullanılarak istatistiksel olarak daha önemli model parametreleri tanımlanmıştır. Bu araştırma için üç değişken vardır: frekans (A), voltaj (B) ve Grafen miktarı (C). İletkenlik kullanılan yöntemin cevabıdır. Çalışma için her biri üç seviyede üç değişken kullanılarak yirmi deney yapılmıştır (Tablo 2). Üç bağımsız değişken arasındaki matematiksel ilişki, aşağıdaki denklemle ifade edilebilir.

$\mathrm{R}=\beta_{0}+\sum_{i=1}^{n} \beta_{i} x_{i}+\sum_{i=1}^{n} \beta_{i i} x i^{2}+\sum_{i=1}^{n-1} \sum_{j=i+1}^{n} \beta_{i j} x_{i} x_{j}$

Burada: $R=$ tahmin edilen cevap (İletkenlik),

$x_{i}, x_{j}=$ bağımsız değişkenler,

$\beta_{0}, \beta_{\mathrm{i}}, \beta_{\mathrm{ii}}, \beta_{\mathrm{ij}}=$ modelin bulduğu katsayılardır.

Tablo 1. Deneysel tasarımda değişken faktörler ve özellikleri

\begin{tabular}{|c|c|c|c|c|c|}
\hline \multirow[t]{2}{*}{ Faktörler } & \multicolumn{5}{|c|}{ Çalışma aralığı ve değerleri } \\
\hline & $-\alpha(-1.682)$ & -1 & 0 & +1 & $\begin{array}{l}+\alpha \\
(+1.682)\end{array}$ \\
\hline$X_{1}(\mathrm{~A})$ : Frekans (Hertz) & 50 & 537.5 & 1025.00 & 1512.5 & 2000 \\
\hline$X_{2}(\mathrm{~B})$ : Voltaj (Volt) & -20 & -10 & 0.000 & 10 & 20 \\
\hline$X_{3}(\mathrm{C})$ : Kütlece grafen yüzdesi & 0 & 2.5 & 5.000 & 7.5 & 10 \\
\hline
\end{tabular}

\section{Bulgular ve Tartışma}

\section{1. Örneklerin FT-IR ve SEM Karakterizasyonu}

Şekil 2, saf poli(VPi-ko-MA) ve poli(VPi-ko-MA)/GF\%8 bileşiklerinin ATR eğrilerini göstermektedir. Spektrum incelendiğinde poli(VPi-ko-MA) ve poli(VPi-ko-MA)/GN'nin pik pozisyonları temel olarak aynıdır ve GN'nin bariz bir absorbans pikinin olmadığı açıktır. Spektrumda, 2974-3053 $\mathrm{cm}^{-1} \mathrm{VPi}$ birimlerine ait metil gruplarını gösterirken, $1700 \mathrm{~cm}^{-1} \mathrm{MA}$ halkasındaki $\mathrm{C}=\mathrm{O}$ grubunun asimetrik 
gerilme titreşim bantlarını göstermektedir [22]. 1845 ve $1767 \mathrm{~cm}^{-1}$ bantları MA halkasındaki simetrik ve antisimetrik gerginliği gösterir. 1190 ve $1143 \mathrm{~cm}^{-1}$ kopolimerdeki $\mathrm{C}=\mathrm{O}$ ve $\mathrm{O}(\mathrm{C}=\mathrm{O})$ anhidrit bantlarıdır.

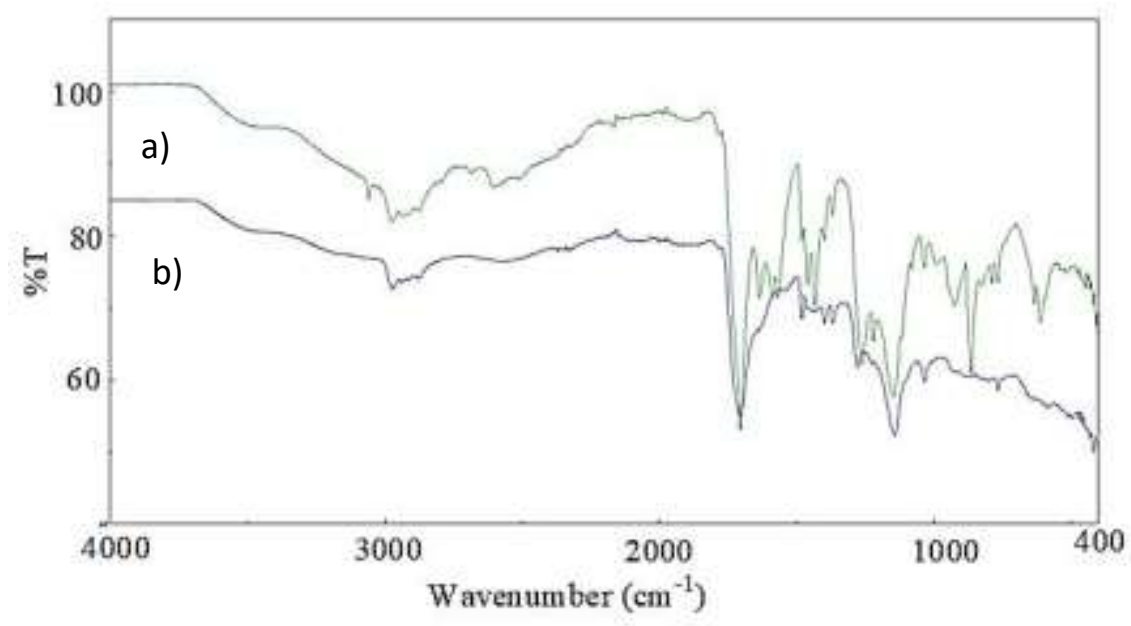

Şekil 2. a) poli(VPi-ko-MA) ve b) poli(VPi-ko-MA)/GF\%8 bileşiklerinin IR spektrumu

Saf poli(VPi-ko-MA) kopolimerinin ve kütlece farklı oranlarda GF (\%2, \%5, \%8, \%10) ile katkılanmış kompozitlerinin yüzey morfolojisi SEM ile karakterize edilmiştir. Şekil 3a, 3b ve 3c'de gösterildiği gibi, hem poli(VPi-ko-MA) hemde poli(VPi-ko-MA)/GF\%2 ve poli (VPi-ko-MA)/GF\%5 kompozitleri gözenekli bir yapıya sahiptir. Grafen yüzdesi arttıkça yüzeyin pürüzsüzleştiği şekil 3d ve 3e'de açıktır. Buda polimerin yüzey alanının GF katmanının yüklenmesi için elverişli olduğunu göstermektedir.
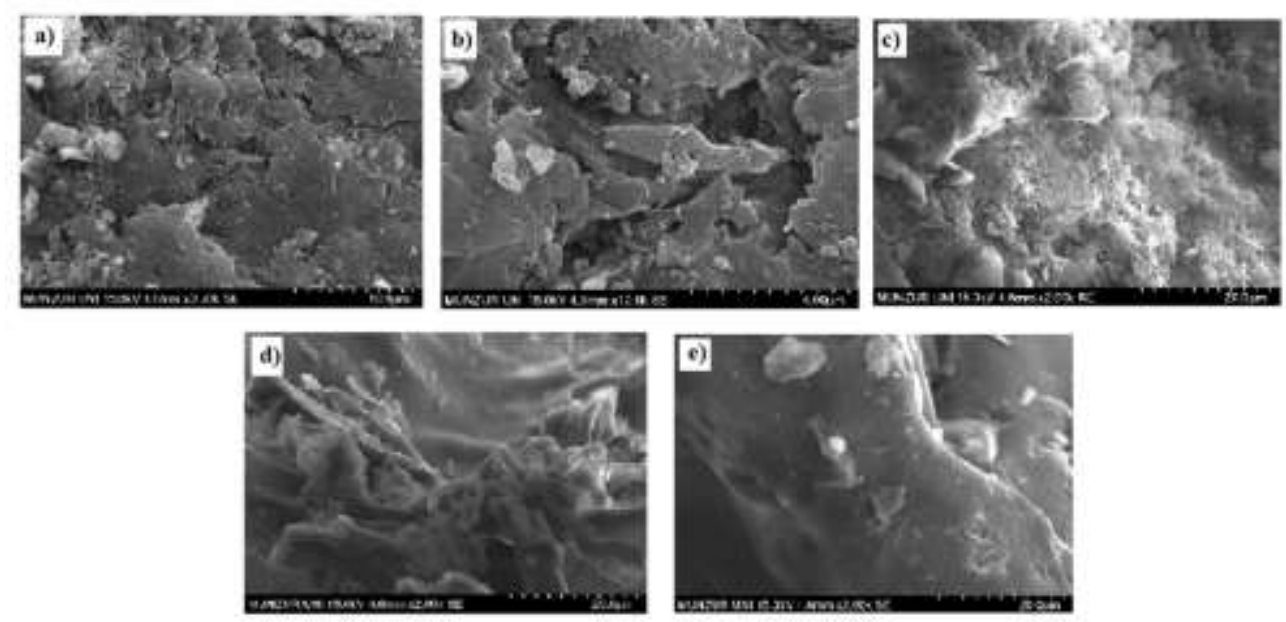

Şekil 3. SEM görüntüleri a) saf poli(VPi-ko-MA) b) poli(VPi-ko-MA)/GF\%2 c) poli(VPi-ko-MA)/GF\%5 d) poli(VPi-ko-MA)/GF\%8 e) poli(VPi-ko-MA)/GF\%10

\subsection{Varyans Analizi ve Optimizasyon}

Bu çalışmada, voltaj, frekans ve grafen miktarı proses değişkenleri olarak seçilmiş ve MKT kullanılarak kompozitlerin elektriksel iletkenliği araştırılmıştır. Tablo 2, bu çalışmada kullanılan MKT deneysel tasarımında 20 deney için değişken değerleri ve iletkenlik sonuçlarını listelemektedir. Poli(VPi-ko-MA) kopolimerin iletkenliği, varyans analizi (ANOVA) kullanılarak istatistiksel olarak analiz edilmiştir ve sonuçlar Tablo 3 'te verilmiştir. Üç değişken ve cevap arasındaki matematiksel ilişki ikinci dereceden polinom denklemi ile aşağıdaki gibi ifade edilebilir. 


$$
\begin{aligned}
\text { iletkenlik }=+ & 4.766 E-009+4.835 E-009 A+6.629 E-012 B+1.370 E-008 C-2.764 E \\
& -012 A B+4.959 E-009 A C+1.061 E-011 B C+6.219 E-010 A^{2}+1.891 E \\
& -010 B^{2}+9.626 E-009 C^{2}
\end{aligned}
$$

Eşitlik 2'deki pozitif işaretler sinerjik etkiyi gösterirken, negatif işaretler anta gonistik etkiyi göstermektedir [23]. Bu eşitliğe göre, frekans $(A)$, voltaj $(B)$ ve grafen miktarı $(C)$ pozitif etkiye sahiptir. Buda poli(VPi-ko-MA) kopolimeri ve poli(VPi-ko-MA)/GF kompozitlerinin iletkenliğinin; frekans, voltaj ve GF miktarı artırıldığı zaman artacağını göstermektedir. Elektriksel iletkenlik için varyans analizi sonuçları (Tablo 3) incelendiği zaman $C$ ve $C^{2}$ 'nin önemli model terimleri olduğu görülmektedir $(P<0.05)$. Değişkenlere ait $P$-değerleri karşılaştırıldığında, GF miktarı için 0,1 den küçük olan değeri bu değişkenin lineer etkisinin önemli olduğunu; bu değişkende yapılacak herhangi bir değişikliğin kompozitin iletkenliğini değiştireceğini göstermektedir. Aynı zamanda GF miktarının $(C)$ lineer

\begin{tabular}{|c|c|c|c|c|}
\hline \multirow{3}{*}{$\begin{array}{l}\text { Deney } \\
\text { Sira No }\end{array}$} & \multicolumn{3}{|c|}{ Bağımsız değişkenler } & \multirow{3}{*}{$\begin{array}{l}\text { Cevap }(Y) \\
\text { iletkenlik } \\
(\mathrm{S} / \mathrm{cm})\end{array}$} \\
\hline & $A$ & $B$ & $C$ & \\
\hline & Frekans, (Hertz) & Voltaj, (V) & Grafen miktarı, (\%wt) & \\
\hline 1 & 445.26 & -11.89 & 2.03 & $1.59 \times 10^{-9}$ \\
\hline 2 & 445.26 & 11.89 & 2.03 & $1.59 \times 10^{-9}$ \\
\hline 3 & 1604.74 & -11.89 & 7.97 & $3.93 \times 10^{-8}$ \\
\hline 4 & 1025 & 0.00 & 5.00 & $4.83 \times 10^{-9}$ \\
\hline 5 & 1025 & 0.00 & 5.00 & $4.79 \times 10^{-9}$ \\
\hline 6 & 1604.74 & -11.89 & 2.03 & $5.51 \times 10^{-9}$ \\
\hline 7 & 1025 & 0.00 & 5.00 & $4.83 \times 10^{-9}$ \\
\hline 8 & 1025 & 0.00 & 5.00 & $4.79 \times 10^{-9}$ \\
\hline 9 & 1604.74 & 11.89 & 7.97 & $3.94 \times 10^{-8}$ \\
\hline 10 & 1025 & 0.00 & 0.00 & $4.37 \times 10^{-9}$ \\
\hline 11 & 1025 & 0.00 & 5.00 & $4.79 \times 10^{-9}$ \\
\hline 12 & 1025 & 0.00 & 10.00 & $5.86 \times 10^{-8}$ \\
\hline 13 & 2000 & 0.00 & 5.00 & $9.23 \times 10^{-9}$ \\
\hline 14 & 1025 & 0.00 & 5.00 & $4.79 \times 10^{-9}$ \\
\hline 15 & 445.26 & -11.89 & 7.97 & $1.56 \times 10^{-8}$ \\
\hline 16 & 50 & 0.00 & 5.00 & $2.88 \times 10^{-9}$ \\
\hline 17 & 445.26 & 11.89 & 7.97 & $1.56 \times 10^{-8}$ \\
\hline 18 & 1604.74 & 11.89 & 2.03 & $5.51 \times 10^{-9}$ \\
\hline 19 & 1025 & 0.00 & 5.00 & $4.79 \times 10^{-9}$ \\
\hline 20 & 1025 & 0.00 & 5.00 & $4.79 \times 10^{-9}$ \\
\hline
\end{tabular}
etkisinin yanında ikinci dereceden etkisinin de oldukça önemli olduğu görülmektedir.

Tablo 2. Deneysel dizayn ve MKT sonuçları.

ANOVA bir deneysel tasarımda hangi faktörün en önemli olduğunu gösterir. Ayrıca, araştırılan faktörler arasındaki ilişkiyi belirler ve deney sonuçlarının anlamlı olup olmadığı hakkında bilgi verir [24]. ANOVA'dan elde edilen sonuçlar Tablo 3'de gösterilmektedir. Modelin $P$ ve $F$ değerleri surasiyla $<0.0001$ ve 34.26'dır. İletkenlik için korelasyon katsayısının yüksek değeri $\left(\mathrm{R}^{2}=0.97\right)$, deneysel veriler ile model arasında iyi bir ilişki olduğunun kanıtıdır. $\mathrm{R}^{2}$ değerinin $\% 97$ olması, iletkenlik için toplam varyasyonun \%97'sinin değişken faktörlere bağlı olduğunu göstermektedir [25].

Elektriksel iletkenlik üzerine her seferinde iki faktörün etkileşim etkilerinin 3D ve kontur grafikleri Şekil 4'de gösterilmiştir. Grafikler, üçüncü parametrenin orta seviyesindeki iki parametre arasındaki ilişkiyi göstermektedir. Şekil 4a'da, AC iletkenliği, frekansla neredeyse doğrusal olarak artmıştır buna neden olarak ara yüzey polarizasyonu ve kompozitlerde meydana gelen dielektrik gevşeme süreçleri gösterilebilir [26]. Ancak artan voltajla iletkenliğin önemli ölçüde değişmediği gözlenmiştir [27]. Şekil 4b, grafen miktarı ve frekans arasındaki ilişkiyi göstermektedir. En yüksek iletkenlik yüksek frekans ve yüksek grafen miktarlarında gözlenmiştir. Özellikle grafen miktarı AC iletkenlik üzerinde önemli bir etkiye sahiptir. Buda ANOVA sonuçlarıyla desteklenmiştir. Voltaja karş1 grafen yüzdesi (Şekil 4c) için yüzey grafiği incelendiğinde grafen miktarı \%10'a yakın iken en yüksek iletkenlik gözlenirken voltajın iletkenlik üzerinde önemli bir etkisi olmadığı açıktır. 
Tablo 3. Elektriksel iletkenlik için varyans analizi

\begin{tabular}{|c|c|c|c|c|c|c|}
\hline Kaynak & $\begin{array}{l}\text { Kareler } \\
\text { toplamı }\end{array}$ & $\begin{array}{c}\text { Serbestlik } \\
\text { derecesi }\end{array}$ & Ortalama kare & $F$ - değeri & $\begin{array}{c}P \text {-değeri } \\
\text { P }>\text { F }\end{array}$ & Anlamlılık \\
\hline Model & $4.425 \times 10^{-15}$ & 9 & $4.916 \times 10^{-16}$ & 34.26 & $<0.0001$ & anlaml1 \\
\hline$A$-Frekans & $3.193 \times 10^{-16}$ & 1 & $3.193 \times 10^{-16}$ & 22.25 & 0.0008 & \\
\hline$B$-Voltaj & $6.002 \times 10^{-22}$ & 1 & $6.002 \times 10^{-22}$ & $4.183 \times 10^{-5}$ & 0.9950 & \\
\hline$C-\%$ Grafen & $2.564 \times 10^{-15}$ & 1 & $2.564 \times 10^{-15}$ & 178.66 & $<0.0001$ & \\
\hline$A B$ & $6.111 \times 10^{-23}$ & 1 & $6.111 \times 10^{-23}$ & $4.258 \times 10^{-6}$ & 0.9984 & \\
\hline$A C$ & $1.967 \times 10^{-16}$ & 1 & $1.967 \times 10^{-16}$ & 13.71 & 0.0041 & \\
\hline$B C$ & $8.999 \times 10^{-22}$ & 1 & $8.999 \times 10^{-22}$ & $6.272 \times 10^{-5}$ & 0.9938 & \\
\hline$A^{2}$ & $5.573 \times 10^{-18}$ & 1 & $5.573 \times 10^{-18}$ & 0.39 & 0.5471 & \\
\hline$B^{2}$ & $5.151 \times 10^{-19}$ & 1 & $5.151 \times 10^{-19}$ & 0.036 & 0.8535 & \\
\hline$C^{2}$ & $1.335 \times 10^{-15}$ & 1 & $1.335 \times 10^{-15}$ & 93.06 & $<0.0001$ & \\
\hline Uyum eksikliği & $1.435 \times 10^{-16}$ & 5 & $2.870 \times 10^{-17}$ & 52.68 & 0.0002 & anlamli \\
\hline Saf hata & 0.000 & 5 & 0.000 & & & \\
\hline
\end{tabular}

$R^{2}=0.97$, Ayarlanmış $R^{2}=0.94$, Tahmini $R^{2}=0.76$, Yeterli hassasiyet=21.14

a)

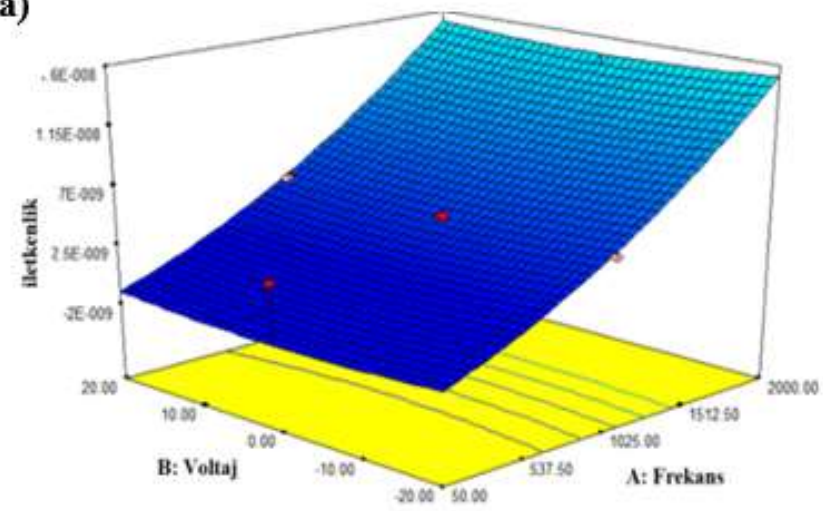

b)
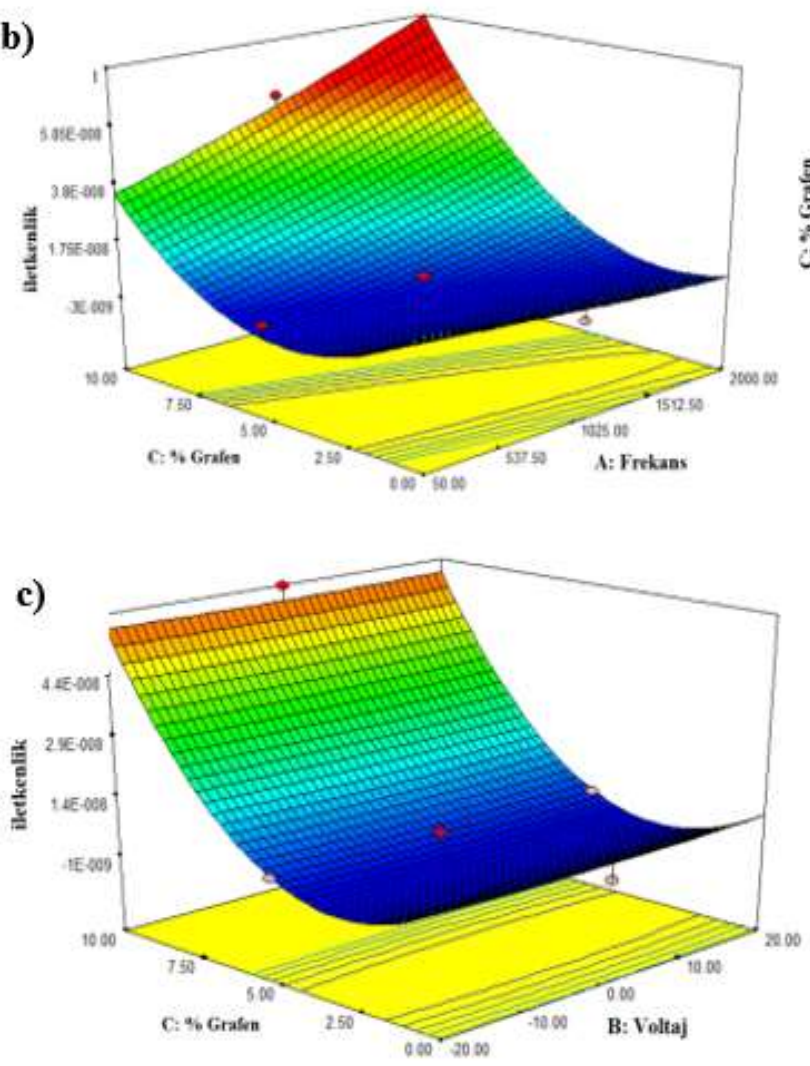

Şekil 4. Farklı deneysel şartlar için poli(VPi-co-MA) kopolimerinin AC iletkenliğinin 3D ve kontur grafikleri
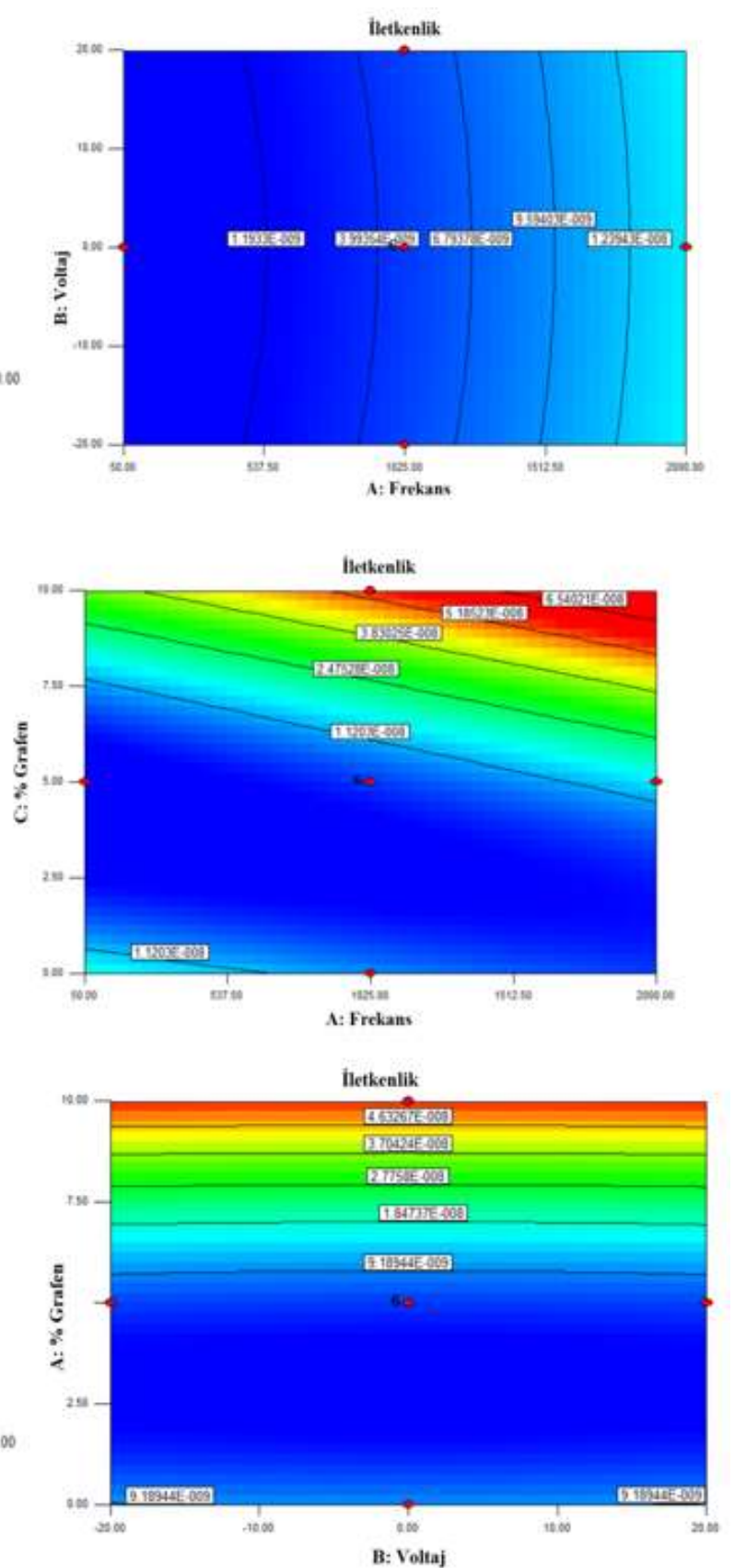
Poli(VPi-ko-MA) kopolimerinin maksimum AC iletkenliği için Desing expert'in desirability programı kullanılmıştır ve optimum şartlar belirlenerek ve Şekil 5'de verilmiştir. Bulunan optimum şartlar, frekans için $1619 \mathrm{~Hz}$, voltaj için 15.56 ve grafen miktarı için \%9.99'dur. Bu şartlarda AC iletkenlik değeri $6.93 \times 10^{-8}$ olarak bulunmuştur.

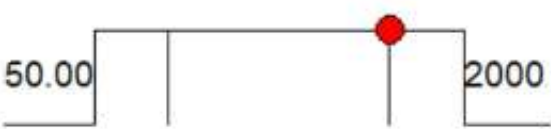

445.26

A:Frekans $=1619$

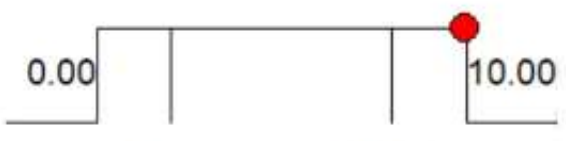

2.03

C: \%Grafen $=9.99$

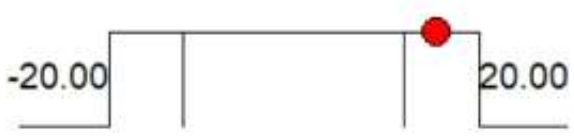

$-11.89$

11.89

B:Voltaj $=15.56$

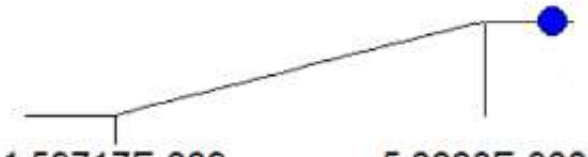

İletkenlik $=6.93 \mathrm{E}-008$

\section{Desirability $=1.000$}

Şekil 5. Maksimum iletkenliği veren parametrelerin optimum değerleri

\section{Sonuç}

$\mathrm{Bu}$ çalışmada, sentezlenen ve karakterize edilen poli(VPi-ko-MA) kopolimerinin en yüksek AC iletkenliği ve optimum proses şartları cevap yüzey yöntemi kullanılarak belirlenmiştir. Merkezi kompozit tasarım, frekans, uygulanan voltaj ve grafen miktarı arasında kantitatif ilişkiler kurmak için kullanılmıştır. Modelde terimlerin önemi varyans analizi (ANOVA) sonuçlarının analizi ile incelenmiş ve istatistiksel olarak önemsiz terimlerin ortadan kaldırılmasıyla daha basit ancak daha verimli model elde edilmiştir. Cevap yüzey yöntemi kullanılarak en yüksek elektriksel iletkenlik değeri $\left(6,98 \times 10^{-8}\right)$ için optimum proses şartları, $1619 \mathrm{~Hz}$ frekans, $15.56 \mathrm{~V}$ voltaj ve $\% 9.99 \mathrm{GF}$ miktarı olarak bulunmuştur. İletkenlik için, ANOVA ile bulunan regrasyon katsayısı $R^{2}=0.97$ 'dir ve toplam varyasyonun sadece \%3'ünün modelle açıklanamadığını göstermektedir. Sonuçlar, elektriksel iletkenliğin MKT modeliyle çok kesin bir şekilde tahmin edilebileceğini göstermiştir. Poli(VPi-ko-MA) kopolimerinin elektriksel iletkenliği, frekans ve grafen \%'sinin artmasıyla önemli ölçüde artmıştır. Voltaj değişikliğinin ise iletkenlik üzerinde önemli bir etkisinin olmadığı görülmüştür.

\section{Yazarların Katkısı}

Çalışmanın tasarlanmasında, deneylerin yapılması ve yorumlanması \%100 yazarın kendisine aittir.

\section{Çıkar Çatışması Beyanı}

Yazarlar arasında herhangi bir çıkar çatışması bulunmamaktadır.

\section{Araştırma ve Yayın Etiği Beyanı}

Yapılan çalışmada, araştırma ve yayın etiğine uyulmuştur. 


\section{Kaynaklar}

[1] Koçyiğit Ü.M., Zengin H.B. 2015. Maleik Anhidrit Vinil Asetat Kopolimerinin Ester ve Karboksilat Tuz Türevlerinin Sentezi ve Karakterizasyonu. Cumhuriyet Üniversitesi Fen Fakültesi Fen Bilimleri Dergisi (CFD), 36 (5): 47-56.

[2] Tavman D.H., Turgut A. 2006. Mikro ve nano boyutlu tanecik katk1l polimer kompozitlerin mekanik özellikleri. Proceedings of 11th International Materials Symposium, April 19-21 Nisan, Denizli, 570-575.

[3] Boztuğ A. 1999. Bazı maleik anhidrit terpolimerlerinin ester türevlerinde bilişimin isısal ve termomekanik özelliklere etkisi. Doktora Tezi, Cumhuriyet Üniversitesi, Fen-Bilimleri Enstitüsü, Sivas.

[4] Godovsky D.Y. 2000. Device applications of polymer-nanocomposites. Advances in Polymer Science, 153: 163-205.

[5] Alexandre M., Dubois P. 2000. Polymer-layered silicate nanocomposites: preparation, properties and uses of a new class of materials. Materials Science and Engineering: R: Reports, 28 (1-2): 163.

[6] Ray S.S., Okamoto M. 2003. Polymer/layered silicate nanocomposites: a review from preparation to processing. Progress in Polymer Science, 28 (11): 1539-1641.

[7] Garcia N.J, Bazan J.C. 2009. Electrical conductivity of montmorillonite as a function of relative humidity: La-montmorillonite. Clay Minerals, 44 (1): 81-88.

[8] Uddin F. 2008. Clays, nanoclays, and montmorillonite minerals. Metallurgical and Materials Transactions A, 39 (12): 2804-2814.

[9] Bao Y.Z., Cong L.F., Huang Z.M., Weng Z.X. 2008. Preparation and proton conductivity of poly(vinylidene fluoride)/layered double hydroxide nanocomposite gel electrolytes. Journal of Materials Science, 43 (1): 390-394.

[10] Li Q., Park O.K., Lee J.H. 2009. Positive temperature coefficient behavior of HDPE/EVA blends filled with carbon black. Advanced Materials Research, 79: 2267-2270.

[11] Geng Y., Liu M.Y., Li J., Shi X.M., Kim J.K. 2008. Effects of surfactant treatment on mechanical and electrical properties of CNT/epoxy nanocomposites. Composites Part A: Applied Science and Manufacturing, 39 (12): 1876-1883.

[12] Liu N., Luo F., Wu H., Liu Y., Zhang C., Chen J. 2008. One step ionic-liquidassisted electrochemical synthesis of ionic-liquid-functionalized graphene sheets directly from graphene. Advanced Functional Materials, 18: 1518-1525.

[13] Geim A.K., MacDonald A.H. 2007. Graphene: exploring carbon flatland. Physics Today, 60 (8): 35-41.

[14] Dreyer R.D., Park S., Bielawski C.W., Ruoff R.S. 2010. The chemistry of graphene oxide. Chemical society reviews, 39: 228-240.

[15] Allen M.J., Tung V.C., Kaner R.B. 2010. Honeycomb carbon: a review of graphene. Chemical reviews, 110 (1): 132-145.

[16] Matsuo Y., Hatase K., Sugie Y. 1999. Selective intercalation of aromatic molecules into alkyltrimethylammonium ion-intercalated graphite oxide. Chemistry Letters, 28 (10): 1109-1110.

[17] Cassagneau T., Fendler J.H. 1998. High density rechargeable lithium-ion batteries self-assembled from graphite oxide nanoplatelets and polyelectrolytes. Advanced Materials, 10 (11): 877-881.

[18] Şengöz O. 2014. Maleik anhidrit içeren kopolimerlerin sentezi, karakterizasyonu ve modifikasyonu. Yüksek Lisans Tezi, Selçuk Üniversitesi, Fen Bilimleri Enstitüsü, Konya.

[19] Nasouri K., Shoushtari A.M. 2017. Designing, modeling and manufacturing of lightweight carbon nanotubes/polymer composite nanofibers for electromagnetic interference shielding application. Composites Science and Technology, 145: 46-54.

[20] Arabia M., Ghaedia M., Ostovan A. 2016. Development of dummy molecularly imprinted based on functionalized silica nanoparticles for determination of acrylamide in processed food by matrix solid phase dispersion. Food chemistry, 210: 78-84.

[21] Dyartanti E.R., Susanto H., Widiasa I.N., Purwanto A. 2017. Response surface method (RSM) for optimization of ionic conductivity of membranes polymer electrolyte poly (vinylidene fluoride) (PVDF) with polyvinyl pyrrolidone (PVP) as pore forming agent. IOP Conf. Series: Materials Science and Engineering 206: 012052. 
[23] Dincer S., Koseli V., Kesim H., Piskin E. 2002. Radical copolymerization of Nisopropylacrylamide with anhydrides of maleic and citraconic acids. European Polymer Journal, 38 (11): 2143-2152.

[24] Kumar R., Singh R., Kumar N., Bishnoi K., Bishnoi N. 2009. Response surface methodology approach for optimization of biosorption process for removal of $\mathrm{Cr}$ (VI), $\mathrm{Ni}$ (II) and $\mathrm{Zn}$ (II) ions by immobilized bacterial biomass sp. Bacillus brevis. Chemical Engineering Journal, 146 (3): 401-407.

[25] Wang B., Okoth O.K., Yan K., Zhang J. 2016. A highly selective electrochemical sensor for 4chloro phenol determination based on molecularly imprinted polymer and PDDA-functionalized graphene. Sensors and Actuators B: Chemical, 236: 294-303.

[26] Tanyol M. 2017. Malahit Yeşili İçeren Atıksuların Fenton Oksidasyon Prosesi İle Renk Gideriminde İşletme Parametrelerinin Optimizasyonu. Frrat Üniversitesi Mühendislik Bilimleri Dergisi, 29 (1): 183-191.

[27] Kar E., Bose N., Dutta B., Mukherjee N., Mukherjee S. 2017. Poly(vinylidene fluoride)/submicron graphite platelet composite: A smart, lightweight flexible material with significantly enhanced $\beta$ polymorphism, dielectric and microwave shielding properties. European Polymer Journal, 90: 442-455.

[28] Hakkak F., Rafizadeh M., Sarabi A.A., Yousefi M. 2015. Optimization of ionic conductivity of electrospun polyacrylonitrile/poly (vinylidene fluoride) (PAN/PVdF) electrolyte using the response surface method (RSM). Ionics, 21 (7): 1945-1957. 